\title{
Antigrade Humerus Interlocking Nailing for Diaphyseal Fractures of Humerus: A Study of Clinical Outcomes
}

\section{Prasanth Ganji *, PR Naidu Pothula, Nandam Ramarao, Raj Kumar Vijay, Bharath chandra katragadda, Yeseswi Tellakula.}

Consultant Orthopedic Surgeon, Vijaya institute of trauma and orthopaedics, Chennai, Tamil Nadu, India.

\begin{abstract}
Back ground: Humerus fractures are commonest in long bone fractures in orthopaedic practice. Apart from conservatives methods surgery is the mainstay in the treatment of humerus fractures. Among the surgical options antigrage nailing, retrograde nailing, plating are the options. Present study was done to analyze the clinical outcomes of antigrade nailing in diaphyseal fractures of humerus.

Materials and M ethods: 12 cases were treated with antigrade interlocking nailing among the 12 cases (11 cases were closed and 1 grade 1 compound) 9 were fresh cases and two were presented after one week of injury. of the 12 cases 8 middle 1/3,3 were middle1/3and distal 1/3 junction and one is segmental fracture. Cases were fallowed for up to three years.

Results: Excellent results were seen in 8 good in 3 where 1 case went to delayed union.

Conclusions: Antigrde humerus nailing is a effective method of diphyseal fractures of humerus. It has advantageous over compression plating as it is less invasive, no blood loss, and no risk of iatrogenic radial nerve palsy. Shoulder stiffness can prevented by meticulous repair of rotator cuff, avoiding proximal protrusion of nail and early institution of physiotherapy.

KEY WORDS: Humerus fracture, Antigrade Nailing, Retorgrade Nailing, Plating, Diaphyseal fracture, Internal fixation.
\end{abstract}

Address for correspondence: Dr. Prasanth Ganji. MS(Ortho), Consultant, Vijaya Institute of Trauma and Orthopedics, Chennai, Tamil Nadu, India. E-M ail: prasanthganji@gmail.com

\begin{tabular}{|c|c|c|}
\hline \multicolumn{3}{|c|}{ Online Access and Article Informtaion } \\
\hline \multirow{4}{*}{$\begin{array}{c}\text { Quick Response code } \\
\text { DOI: } 10.16965 \text { ijims.2015.122 }\end{array}$} & \multirow{2}{*}{\multicolumn{2}{|c|}{$\begin{array}{l}\text { International Journal of Integrative Medical Sciences } \\
\text { www ww.imedsciences.com }\end{array}$}} \\
\hline & & \\
\hline & Received: 02-08-2015 & Accepted: 20-09-2015 \\
\hline & Reviewed: 02-08-2015 & Published: 30-09-2015 \\
\hline Source of Funding: Self & \multicolumn{2}{|c|}{ Conflicts of interest: None } \\
\hline
\end{tabular}

\section{BACKGROUND}

Road traffic accidents ranks first among all accidents followed by industrial accidents, falls, railway accidents and assaults leading to high incidence of morbidity and mortality. Humerus is one of the commonest among long bone fractures. Diaphyseal fractures are complicated by radial nerve palsy because of its close proximity of the nerve to bone in middle one third region.

In the words of Sir John Charnely it is perhaps the easiest of the major long bones to treat by conservative methods. M ost of the fractures of the shaft of the humerus treated conservatively are clinically united by about six weeks which was known as far back as the time of Hippocrates. Unfortunately not all the fractures of shaft of humerus behave in this way.

Internal fixation may be required for patients with more than one fracture in the same limb, for double fractures or where there are multiple fractures of humerus or multiple fractures elsewhere in the body and associated neuro vascular injuries. 
Internal fixation of fracture shaft of humerus allows ready access for nursing care in patients with multiple injuries and associated co morbid conditions. And also restrictive bandages and splints are avoided, early mobilization of the patients and his limbs helps to prevent fracture disease.

Intramedullary interlocking nailing has become the standard method of management for closed diaphyseal fracture of long bones [1]. Being close to the weight bearing axis, an intramedullary nail is at a mechanical advantage over other fractrure stabilization devices such as plates [2,3], external fixator and casts. The intramedullary nailing can be inserted in reamed or unreamed fashion with its own merits and demerits. The initial unlocked design was modified to allow proximal and distal interlocking. This further improved stability and expanded the indication for the nailing to include comminuted fractures and more proximal and distal fractures.

The present study is done to evaluate the outcomes antigrade interlocking nailing in diaphyseal fractures.

\section{MATERIALS AND METHODS}

In all 12 cases closed reduction and internal fixation done with antegrade intramedullary interlocking nail [4]. Both proximal and distal locking done performed.

General anesthesia is used in all 12 cases; we positioned the patient supine with pillow below the shoulder girdle with patient head turned to opposite side to maximize exposure of shoulder under image intensifier.

We obtained reduction of fracture by closed manipulation of fracture under image intensifier $\&$ checked both in anteroposterior \& lateral views.

In all 12 cases, we used a longitudinal skin incision [5] starting from the most lateral point of the acromion and extending distally, centered over the tip of the greater tuberosity. We are cautious not to extend the incision more than 4$5 \mathrm{~cm}$ in deltoid muscle in order to avoid damage to axillary nerve.

In all 12 cases procedure carried out by antegrade technique [6]. Entry point was made with bone awl medial to the tip of greater tuberosity. The bone awl was advanced by rotatory movements until it is seated within the humeral head.

The position of bone awl was confirmed by image intensifier by taking anteroposterior \& lateral views. The position of bone awl was adjusted under image control so that entry portal was centered both in anteroposterior \& lateral views to ensure that nail will be in the mid plane of humerus.

Then $2.4 \mathrm{~mm}$ ball tipped guide wire was advanced through the entry point into the medullary cavity. Fracture site was held reduced $\&$ guide wire was advanced from proximal to distal fragment \& confirmed by image intensifier by anteroposterior \& lateral views. We advanced the guide wire into distal fragment until tip is 1 to $2 \mathrm{~cm}$ proximal to the olecranon fossa.

For measuring required nail length we used guide wire method. In this method with distal end of guide wire 1 to $2 \mathrm{~cm}$ proximal to olecranon fossa [7], overlapped with a second guide wire under image intensifier. Extending proximally towards the humeral entry point. Nail length was obtained by subtracting overlapped length in millimeters from $500 \mathrm{~mm}$.

In the present study reaming was done in ten cases. We reamed the entire humerus over the $2.4 \mathrm{~mm}$, ball tipped guide wire in $0.5 \mathrm{~mm}$ increments until the desired diameter is achieved.

We used a medullary exchange tube over the $2.4 \mathrm{~mm}$ balltipped guide wire $\&$ exchanged with a $2.4 \mathrm{~mm}$ guide wire without ball tip.

We attached the selected nail to the proximal jig with conical bolt with outtigger handle pointing away from the patient and proximal curvature of nail pointed laterally.

Nail was driven over the guide wire by gentle movements of the jig upto fracture site, fracture reduction was confirmed in both anteroposterior \& lateral views by image intensifier \& advanced gently over the fracture site to the distal fragment to avoid comminution at fracture site.

Guide wire was removed \& humeral driver was attached to the jig \& nail was advanced by gentle tapping until it is 1 to $2 \mathrm{~cm}$ proximal to olecranon fossa. 
Proximal locking was done with the help of jig $.8 \mathrm{~mm}$ drill sleeve was passed through proximal drill guide $\&$ pushed to the bone by small skin incision. $2.7 \mathrm{~mm}$ humeral drill sleeve was passed through $8 \mathrm{~mm}$ sleeve. $2.7 \mathrm{~mm}$ trochar was used to make dimple on outer cortex. 2.7 $\mathrm{mm}$ drill bit was used to drill from lateral to medial side. Drill was removed size of screw was determined by humeral screw length gauge. The selected $4 \mathrm{~mm}$ fully threaded screw was inserted.

Distal locking was done by free hand technique [8]. We used anterior approach where small skin incision was given $\&$ biceps muscle was split by blunt dissection. Distal hole drilled anteroposterior direction with $2.7 \mathrm{~mm}$ drill bit under image guidance. Appropriate screw length was measured by humeral screw length guage and desired $4 \mathrm{~mm}$ screw was inserted. Both incisions were thoroughly irrigated with saline, hydrogen peroxide and closed in layers. The cases were followed at regular intervals and the following details were noted.

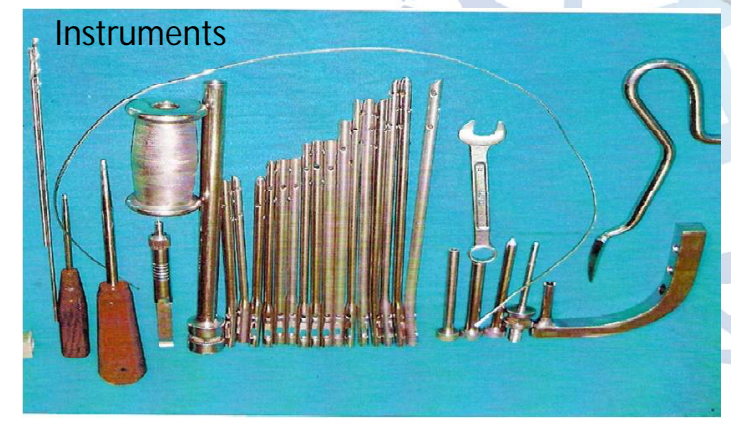

Preparation and drapping

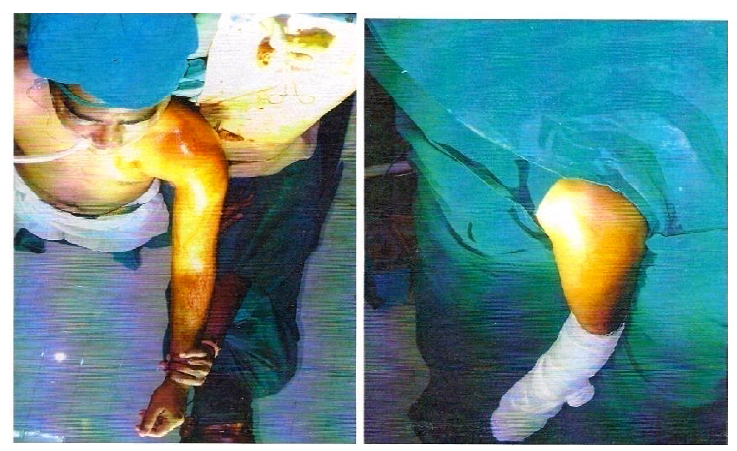

entry point

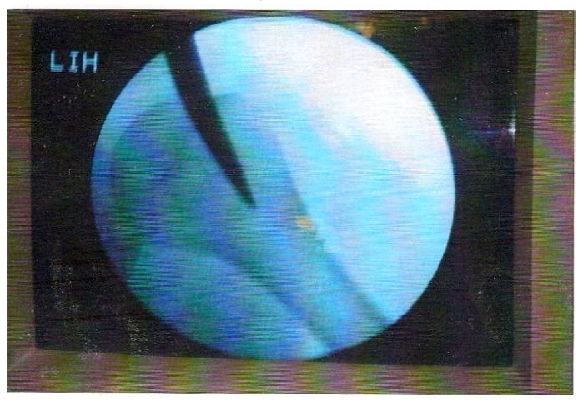

Int J Intg M ed Sci 2015;2(9):152-56. ISSN 2394 - 4137

\section{CLINICAL ASSESSM ENT}

Skin, Swelling, Tenderness at Fracture Site, Deformity and Disability, Neurological Examination.

Shoulder: Abduction, Flexion, Extension, Internal Rotation, External Rotation

Elbow: Flexion

\section{Radiological Assessment:}

Fracture Reduction, Fracture Union:

In the present study 12 cases of fracture shaft humerus treated by closed reduction and fixation with the interlocking nail, the anatomical and functional results are evaluated based on the criteria mentioned above. (Naiman, PT Schein, A.J.Et.A11970).

Excellent: Clinically sound union and radiologically good union. Full range or near normal active range of motion at shoulder and elbow. No deformity and disability, No post operative complication (Radial nerve injury, infection etc.).

Proximal locking
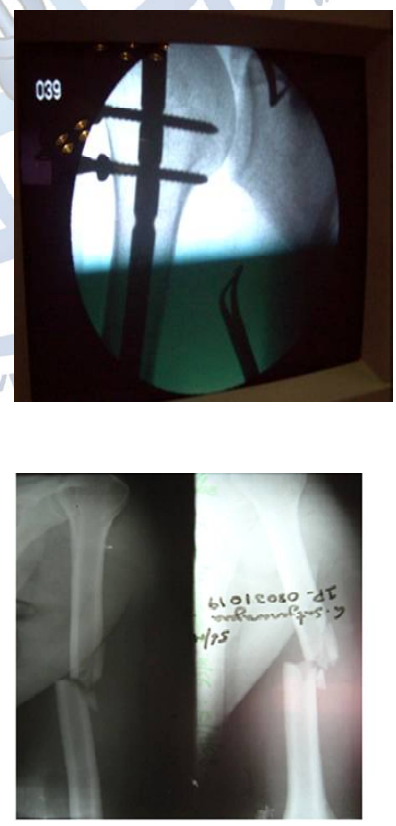

PRE OPERATIVE RADIOGRAPH

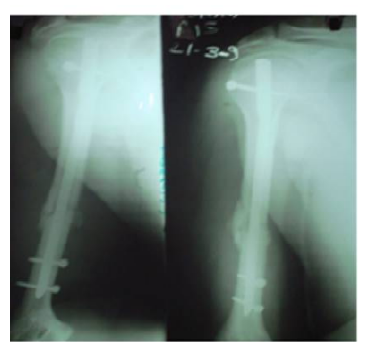

NTHS POST OPFRATIVF. RADIOSR APH
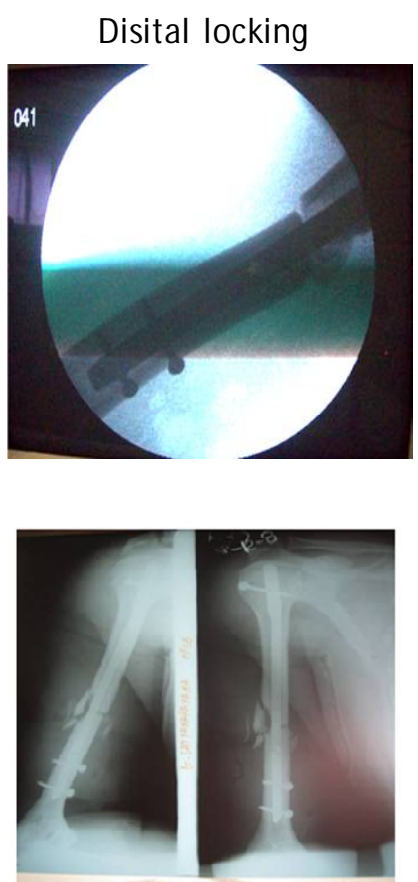

POST OPERATIVE RADIOGRAPH

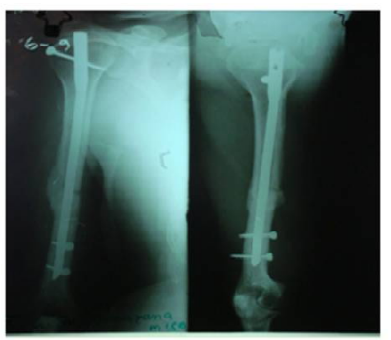

6 MONTHS POST OPERATIVE RADIOGRAP: 
Good: Clinically and Radiologically sound union, $70 \%-90 \%$ of active range of motion at shoulder and elbow, no shoulder, elbow stiffness, No deformity and disability, No post operative complication.

Fair: Clinically and Radiologically delayed union, $50 \%$ to $70 \%$ of active range of motion, associated with stiffness of shoulder and elbow, Mild degrees of post operative complications like superficial infection, No deformity and disability.

Poor: Clinically and radiologically non union, Less than $50 \%$ of active range of motion at shoulder and elbow.Post operative complications, Deformity and disability.

\section{RESULTS}

In this series there were 10 male and 2 female patients. Age incidence varied from 20 years to 65 years and 5 cases were in the age group of 20 to 30 years and 4 cases were in the age group of 30 to 50 years. 3 cases were in age group 50-65 years. The left humerus was involved in 5 cases and remaining 7 cases were on the right side.

12 cases are closed fractures. Out of which 8 were located in M iddle $1 / 3^{\text {rd }} \& 3$ were in Middle $1 / 3^{\text {rd }} \&$ distal $1 / 3^{\text {rd }}$ junction 1 was segmental fracture of humerus.Type $A 3$ fractures were commonly representing 6 cases, Type $A 2$ was 1 case, Type B2 were 2 cases, Type B3 were 2 cases, Type $C 2$ was 1 case.The cause of fracture was RTA in 10 cases and fall from tree in 2 cases.

Excellent results were seen in 8 good in 3 where 1 case went to delayed union which was treated by bone grafting.

\section{DISCUSSION}

The technique of interlocking nailing represents the simpler approach of the treatment of humeral fractures. Interlocking nailing [9] also avoids complications like lack of rotational control, migration of nail and requirement of supplementary bracing. The seidel nail was the first nail to be tested clinically.

This was study between involving 12 antegrade reamed humeral shaft fractures. All the nails were inserted antegrade through entry point just medial to greater tuberosity. All these fractures were fixed using a humeral nail of sizes $6,7,8$ $\mathrm{mm}$ diameter and of appropriate length calculated intraoperatively.

In 7 patients the operated limb was immobilized for two days and active assisted shoulder mobilization was started from $3^{\text {rd }}$ postoperative day. In 3 patients mobilization of the shoulder was delayed due to associated injuries. We followed up 12patients for three years.

Radiological union was defined as the presence of bridging callus of the cortices in two orthogonal views. Delayed union was defined as failure of fracture union to occur by 4 months. Non union was defined as failure of fracture union by six months.

Union: Out of 12 cases 11 cases were united 3 to 4 months. 1 delayed union occurred in 6 months. None of the cases had splintering of at the fracture site during nail insertion into distal fragment. Overall union rate $83.3 \% \&$ non union rate is $16.6 \%$ compared with study of $M$. Ajmal et al. (2001) \& Cox M .A et al (2000).

Functional outcome: The main concerns in antegrade intramedullary interlocking nailing of humeral shaft fractures are with shoulder stiffness. Previous reports have implicated injury to the rotator cuff, disruption of the articular cartilage or adhesive capsulitis as a result of antegrade entry. In the antegrade approach, it is essential to ensure that both the nail and proximal locking screws are deep to the cortex to reduce impingement. Functional assessment was defined as per Benzamin Shaffer et al. and Douglas et al. criteria.

All of the 11cases had good to excellent functional rating. In 1delayed union which was treated with bone grafting.

Complications: None in this series had intraoperative splintering at the fracture site while passing the nail into the distal fragment. None in this series developed radial nerve palsy. Bell2 and Vander Griend reported 2.9\% radial nerve palsy following plating [10] of humeral shaft fractures. None of the patients underwent implant removal in our follow up.So our study shows that early fixation of fracture by closed reduction and internal fixation with intramedullary interlocking nail had resulted in early fracture union and early return to the 
functional and occupational activities. The study also coincides with results of $\mathrm{M}$. Ajmal et al. (2001) and Cox M .A. et al. (2000) in their study found that interlocking nail is beneficial to the patients with fracture shaft of humerus as it results in early return to functional ability with near normal union.

\section{CONCLUSIONS}

Humeral interlocking nail is an effective means of fixation of acute humeral fractures. It is also of special value in open humeral fractures due to lower incidence of infections. Distraction at the fracture site should be avoided. Shoulder stiffness is a significant problem in antegrade nailing, which can be minimized if care is taken to prevent proximal protrusion of the nail and repair the rotator cuff properly and early institution of physiotherapy.

\section{REFERENCES}

1. Cox M A, Dolan M, Synnott K, M celwain JP. Closed Interlocking Nailing of Humeral Shaft Fractures with the Russell-Taylor Nail. Orthop Trauma 2000;14;349-353.

2. Bell MJ, Beauchamp CG, Kellam JK, M cM urthy Ry. The results of plating Humeral shaft Fractures in Patients with Multiple Injuries. JBJS Br.1985;67;293-296.
3. Brumback RJ, Bosse MJ, Poka A, Burgess AR. Intramedullary stabilization of Humeral Shaft Fractures in Patients with Multiple Trauma. JBJS Am. 1986;68;960-970.

4. M Ajmal, M O'Sullivan, J Mc Cabe, W Curtin. Antegrade locked intramedullary nailing in humeral shaft fractures. Injury 2001;32(9):692-4.

5. Stanley Hoppenfeld MD, Piet deBoer MA FRCS, Richard Buckley M D FRCSC. Surgical Exposures in Orthopaedics: The Anatomic Approach (Hoppenfeld, Surgical Exposures in Orthopaedics) Fourth Edition.

6. Crates J, Whittle PA. Antegrade interlocking nailing of Acute Humeral Shaft Fractures. Clin Orthop.1998;350;40-50.

7. Dobozi WR. Flexible intramedullary nailing of humeral shaft fractures. In: Browner BD, ed. The science and practice of intramedullary nailing: Lea and Febiger; 1987;305-318.

8. Cox M A, Dolan M, Synnott K, M celwain JP. Closed Interlocking Nailing of Humeral Shaft Fractures with the Russell-Taylor Nail. Orthop Trauma 2000;14; 349-353.

9. Chapman J R, Henley M B, Julie A, Benca PJ. Randomized Prospective Study of Humeral Shaft Fracture fixation: Intramedullary Nails Versus Plates. J Orthop Trauma. 2000; 14; 162-166.

10. Holstein A, Lewis G.B. Fractures of the humerus with radial nerve paralysis. J Bone Joint Surg. 1963;45:1382-1388.

How to cite this article: Prasanth Ganji, PR Naidu Pothula, Nandam Ramarao, Raj Kumar Vijay, Bharath chandra katragadda, Yeseswi Tellakula. Antigrade Humerus Interlocking Nailing for Diaphyseal Fractures of Humerus: A Study of Clinical Outcomes. Int J Intg M ed Sci 2015;2(9):152-156. DOI: 10.16965/ijims.2015.122 